\title{
Neurite Outgrowth Patterns in Cerebellar Microexplant Cultures are Affected by Antibodies to the Cell Surface Glycoprotein L1
}

\author{
Günther Fischer, Volker Künemund, and Melitta Schachner \\ Department of Neurobiology, University of Heidelberg, 6900 Heidelberg, F.R.G.
}

To probe for the role of the $\mathbf{L} 1$ cell surface glycoprotein during neurite outgrowth and fasciculation in the early postnatal mouse cerebellar cortex, a microexplant culture system was used. Fasciculation of neurites was reduced in the presence of antigenbinding fragments (Fab) of poly- and monoclonal L1 antibodies, as compared to untreated controls. In addition, speed of neurite outgrowth was enhanced in the presence of antibodies. Migration of cell bodies of small neurons was also significantly increased. Very similar effects on these outgrowth parameters were observed with Fab fragments from poly- and monoclonal neural cell adhesion molecule (N-CAM) antibodies. Antibodies from preimmune sera had no effect. These findings suggest that L1 antigen not only plays a role in adhesion of isolated neural cell bodies and migration of granule cell neurons in the early postnatal mouse cerebellar cortex (Lindner et al., 1983; Rathjen and Schachner, 1984), but also in neurite outgrowth and fasciculation.

The formation of the mammalian nervous system depends on the coordinated sequence of separate events that have been defined as neural induction, cell proliferation, migration, aggregation, cytodifferentiation, cell death, and synapse formation and elimination (Cowan, 1982). Cell surface interactions are considered to play a crucial role in at least some of these processes. The process of cytodifferentiation, which underlies the morphological and biochemical maturation of neural cells, includes the elaboration of neurites, specialized as axons or dendrites, in their unique three-dimensional deployment. The extension of cellular processes has been shown to require growth factors, such as NGF, which promotes neurite outgrowth of some neurons from the peripheral nervous system (see, e.g., Greene and Shooter, 1982). In addition, it is likely that outgrowing neurites probe their immediate surroundings by surface contacts between growth cone, leading process or neurite shaft, and cellular or acellular matrix environment (Lander et al., 1983; Landis, 1983; Letourneau, 1983). These contacts require differential adhesive and de-adhesive forces among the partners involved. The equilibrium between these forces determines the eventual morphogenetic pattern. The cellular and molecular mechanisms that shape these interactions have yet to be elucidated. We have recently characterized, by use of monoclonal antibodies, a new cell surface glycoprotein, $\mathrm{L} 1$, which is involved in a $\mathrm{Ca}^{2+}$-independent adhesion among neural cells and the migration of granule cell neurons in the early postnatal mouse

\footnotetext{
Received Feb. 8, 1985; revised June 3, 1985; accepted July 2, 1985.

The authors are grateful to Bernd Gehrig and Christa Raab for technical assistance; Drs. A. Faissner, L. Eng, and B. Bizzini for antibodies and tetanus toxin; Dr. C. Goridis for hybridoma cells; and the Deutsche Forschungsgemeinschaft for support (Fi 327/1-1 and Scha 185/8-4).

Correspondence should be addressed to Dr. Melitta Schachner, Department of Neurobiology, University of Heidelberg, Im Neuenheimer Feld 504, $6900 \mathrm{Hei}-$ delberg, F.R.G.

Copyright $@ 1986$ Society for Neuroscience $0270-6474 / 86 / 020605-08 \$ 02.00 / 0$
}

cerebellar cortex (Faissner et al., 1984a; Keilhauer and Schachner, 1985; Lindner et al., 1983; Rathjen and Schachner, 1984). Expression of Ll glycoprotein has so far been localized only to neurons in the central nervous system and to neurons and glia in the periphery (Faissner et al., 1984b). During development of the mouse cerebellar cortex, granule cell neurons express L1 first after they have ceased to proliferate and before they have started to migrate inward from the external to the internal granular layer (Rathjen and Schachner, 1984). The antigen is detectable on the cell body and concomitantly on the nascent axons of the postmitotic, premigratory granule cells that are to form the densely packed parallel fibers in the molecular layer. After migration, L1 is expressed for several days by postmigratory granule cells on the cell body and processes, but has disappeared from cell bodies and persists only on axons in adulthood.

The present study was undertaken to investigate the functional role of $\mathrm{L} 1$ expression on granule cell axons. A microexplant culture system was developed for this purpose that allowed the quantitative assessment of neurite outgrowth pattern in the early postnatal mouse cerebellar cortex. We could show that speed and pattern of neurite outgrowth, and movement of neuronal cell bodies, are affected by antigen-binding fragments (Fab) of poly-and monoclonal antibudies to $\mathrm{L} 1$ and neural cell adhesion molecule (N-CAM).

\section{Materials and Methods}

\section{Animals}

C57BL/6J mice were bred at the animal facilities of the Department of Neurobiology.

\section{Antibodies}

Mono- and polyclonal L1 antibodies were obtained as described previously (Rathjen and Schachner, 1984). Mono- and polyclonal antibodies to N-CAM/BSP-2 were prepared as described previously (Goridis et al., 1983). The specificity of these antibodies has been described (Faissner et al., 1984a). Preimmune antibodies were obtained from unimmunized rabbits. Fab fragments were prepared by proteolytic digest with papain, as referred to elsewhere (Rathjen and Schachner, 1984).

\section{Culture medium}

A serum-free, hormone-supplemented medium was used (Fischer, 1982). It contained fally acid-free BSA (1 mg/ml; Serva, Heidelberg), insulin $(10 \mu \mathrm{g} / \mathrm{ml} ;$ Serva), transferrin (100 $\mu \mathrm{g} / \mathrm{ml} ;$ Sigma, Munich), aprotinin (1 $\mu \mathrm{g} / \mathrm{ml}$; Sigma), and thyroxine ( $0.1 \mathrm{~nm}$; Serva). Glucose, glutamine, and the antibiotics, streptomycin and penicillin, were added as described (Fischer, 1982).

\section{Microexplant cultures}

Cerebella were taken from 6-d-old mice, quickly transferred to culture medium, and freed from meninges, choroid plexus, and deep cerebellar nuclei with fine forceps. The remaining tissue was then forced through a Nitrex nylon mesh, pore size $300 \mu \mathrm{m}$ (Moonen et al., 1982). The small 

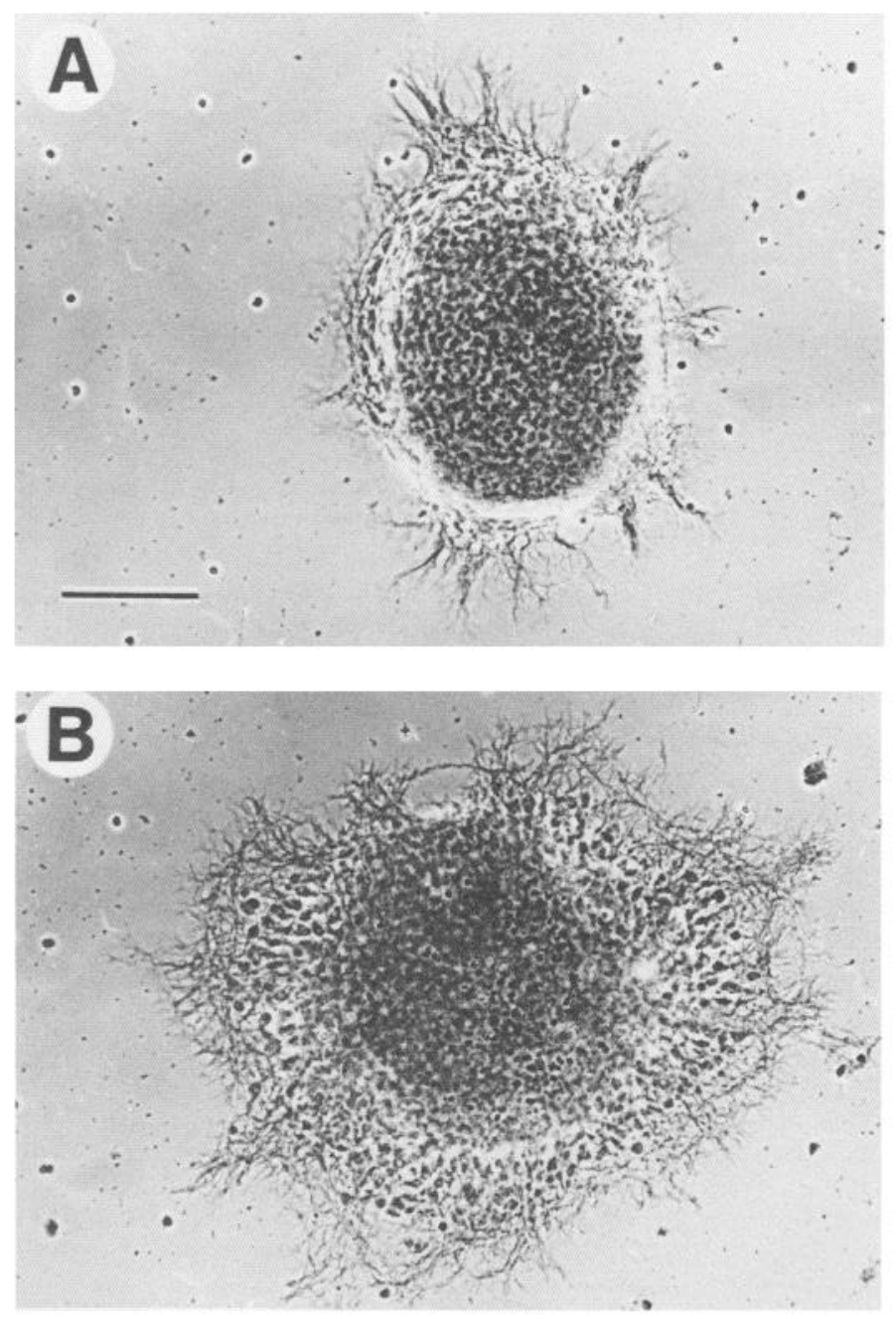

Figure 1. Cerebellar microexplant cultures after $2 \mathrm{~d}$ in culture without $(A)$ and with $(B)$ Fab fragments of monoclonal $\mathrm{L} 1$ antibodies. Sixteen hours after plating, antibodies were added at $0.3 \mathrm{mg} / \mathrm{ml}$ of culture medium. Thirty-two hours later, cultures were fixed for examination by phase-contrast microscopy. Bar, $100 \mu \mathrm{m}$.

tissue pieces were then washed $3 \times$ in culture medium by sedimentation at $1 \times g$ for $5 \mathrm{~min}$ each at room temperature and plated onto poly-Dlysine-coated coverslips ( $16 \mathrm{~mm}$ diameter) in approximately $50 \mu \mathrm{l} \mathrm{cul}$ ture medium per coverslip. Two to three coverslips were placed in one Petri dish ( $35 \mathrm{~mm}$ diameter). Sixteen hours after plating, $1 \mathrm{ml}$ culture medium was added per Petri dish, containing Fab fragments of monoand polyclonal L1 or N-CAM antibodies that had been dialyzed extensively against culture medium prior to addition. Concentrations of Fab fragments ranged from 0.3 to $1.5 \mathrm{mg} / \mathrm{ml}$. In control cultures, $1 \mathrm{ml}$ culture medium without antibody was added. Microexplants were then maintained in a $\mathrm{CO}_{2}$ incubator at $35.5^{\circ} \mathrm{C}$ for several days without change of culture medium.

\section{Immunocytological procedures}

Microexplant cultures were immunolabeled for tetanus toxin receptors, which in the early postnatal mouse cerebellar cortex are specific for neurons (Schnitzer and Schachner, 1981) or for L1 antigen, as described previously (Rathjen and Schachner, 1984; Schnitzer and Schachner, 1981). In some experiments, double immunolabeling for glial fibrillary acidic (GFA) protein, a marker for mature astrocytes (Bignami et al., 1972), or for vimentin, a marker for immature and mature astrocytes (Schnitzer et al., 1981) and tetanus toxin receptors or L1 antigen, were carried out as described (Rathjen and Schachner, 1984; Schnitzer and Schachner, 1981). Staining of oligodendrocytes with O4 antibodies was performed as described (Sommer and Schachner, 1981).

\section{Nuclear- and membrane-staining procedures}

To monitor the localization of cell bodies in vitro, DNA staining was performed with bisbenzimide (H 33342; Riedel-De Haen, Seelze-Hannover) (Rathjen et al., 1981). Microexplants were fixed for $5 \mathrm{~min}$ at room temperature in PBS containing 4\% paraformaldehyde and $1 \%$ glutaraldehyde. After extensive washing in distilled water, microexplants were treated with $2.5 \mu \mathrm{g}$ bisbenzimide/ $\mathrm{ml}$ distilled water for 1 min at room temperature. After one washing in distilled water, coverslips were mounted on glass slides in glycerol/PBS (9:1, vol/vol) containing $2.5 \% \mathrm{NaI}$

To visualize cellular processes better than by phase-contrast microscopy alone, cultures were treated with rhodamine-B-isothiocyanate (RITC) according to Amante et al. (1972). Microexplant cultures were fixed, as described in the last paragraph, with paraformaldehyde and glutaraldehyde, rinsed extensively in distilled water, and stained in 50\% methanol in water with $0.15 \mathrm{mg} \mathrm{RITC} / \mathrm{ml}$ for $2 \mathrm{hr}$ at room temperature. After extensive washings in $50 \%$ methanol in water, the coverslips were mounted on glass slides (see the previous paragraph).

For examination of microexplant cultures by phase contrast and fluorescence microscopy, using an inverted ICM 405 microscope (Zeiss), cultures were fixed, rinsed, and mounted on glass slides (see above). To evaluate the outgrowth pattern of neurites and the migration of cell bodies in a semiquantitative manner, several categories were defined (see Fig. 7). Explants were classified according to these categories in a double-blind procedure. Several independent evaluations of the same experiment yielded identical results.

\section{Results}

When cerebellar microexplants are plated on poly-D-lysinecoated coverslips in serum-free, hormone-supplemented medium, they attach to their substrate within a few hours. After $2 \mathrm{~d}$ in vitro, cell processes that have left the explant core in a more random outgrowth pattern are visible (Fig. $1 A$ ). These processes are identified as neurites by their reactivity with tetanus toxin and L1 antibodies (not shown). Four days after plating, neurites have extended further from the microexplants and fasciculation is more extensive (Figs. $2 B, 3$ ). Neurites continue to extend for up to $6 \mathrm{~d}$, the longest time period studied. Outgrowth of glial fibrillary acidic (GFA) protein and vimentin-positive astrocytic processes from the explant core occurs later than neurite outgrowth (Fig. 4). Astrocytic processes extend from the explant core in a somewhat radial fashion to a maximal distance of approximately one core diameter within 3-4 d in vitro (Fig. 2). Sometimes, cell bodies of astrocytes also leave the explant within this time period, but have not been observed to reach the outer limits of neurite outgrowth.

Movement of small, tetanus toxin receptor-positive neuronal cell bodies from the explant does not depend on the presence of underlying astrocytic processes, which are all both vimentinand GFA protein-positive. Although neuronal cell bodies start their movement at the time of astrocyte outgrowth, they are clearly able to migrate on an astrocyte-free substrate in approximately $50 \%$ of the explants (see Fig. 4). The maximal distance reached by neuronal cell bodies is attained within 3-4 d after plating, by which time the extent of the outgrowth zone of neuronal cell bodies corresponds roughly to the area covered by astrocytic processes (Fig. 2).

Fasciculation of neurites is easily detectable in the periphery, which is free of astrocytic processes, while the tendency to fasciculate appears less pronounced when neurites are in contact with astrocytes (Fig. $2 B$ ). Neurite tips and growth cones in the periphery are seen in bundles (Fig. 5). Fine extensions of neurites and growth cones are L1-antigen-positive (not shown). Occasionally, single O4-antigen-positive oligodendrocytes can be seen, but they never seem to interfere with the neurite outgrowth patterns (Fig. 6). In general, these oligodendrocytes are situated on top of neurites and not underneath, as is the case with astrocytes.

Addition of Fab fragments of mono- and polyclonal L1 antibody $16 \mathrm{hr}$ after plating the microexplant, and maintenance 

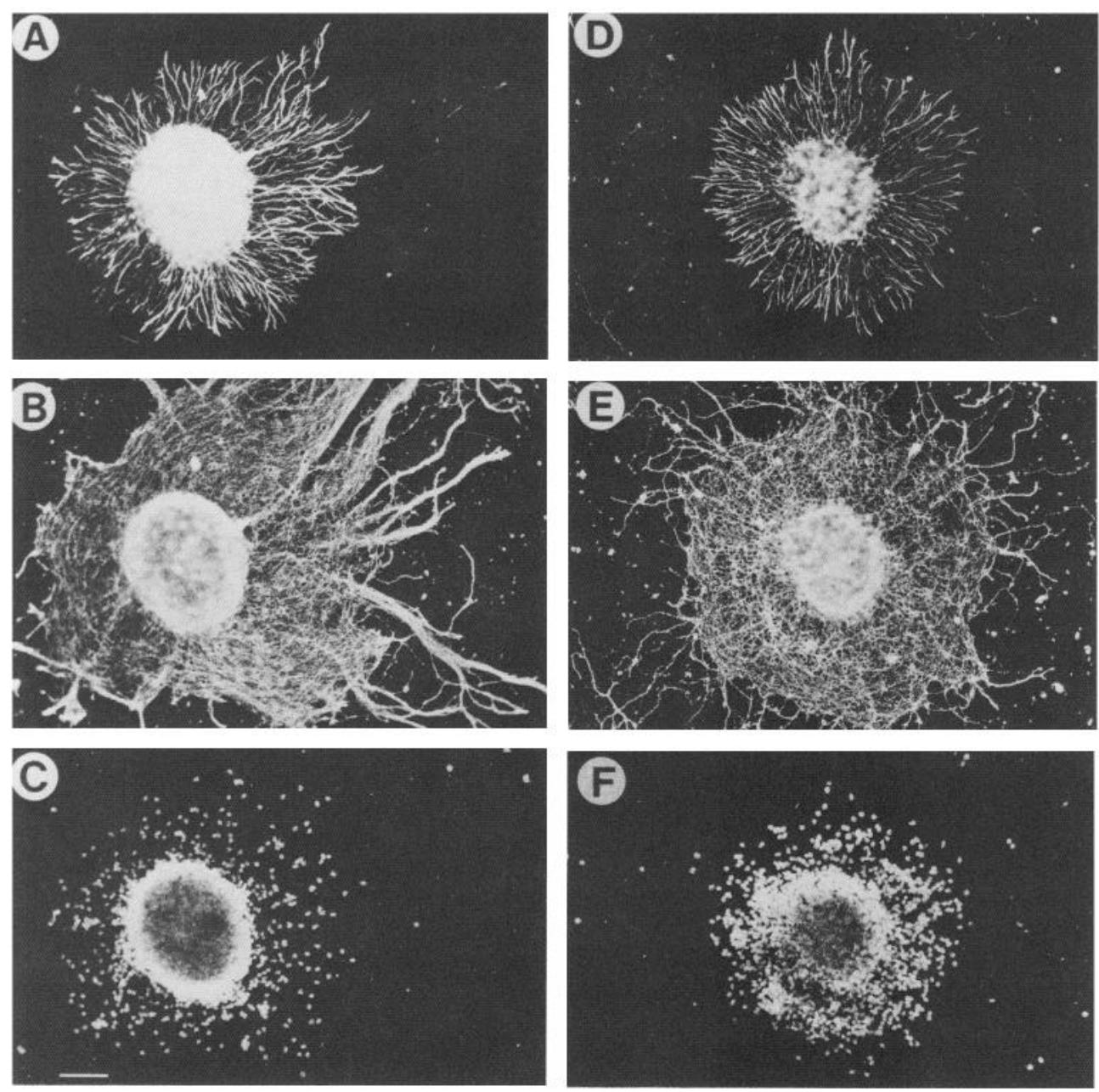

Figure 2. Immunodouble-labeling of cerebellar microexplant cultures for GFA protein $(A, D)$ and tetanus toxin receptors $(B, E)$ in the absence $(A-C)$ or presence $(D-F)$ of Fab fragments of monoclonal $\mathrm{L} 1$ antibodies $(0.3 \mathrm{mg}$ / $\mathrm{ml})$. Cultures were supplemented with antibodies $16 \mathrm{hr}$ after plating and processed for immunodouble-labeling 3 d later. Nuclear staining of cells is shown in the corresponding micrographs $(C, F)$ for $A, B$ and $D, E$, respectively. Bar, $100 \mu \mathrm{m}$. of cultures in the presence of antibody for another day results in a different outgrowth pattern from that of the control (Fig. 1). Neurites extend more quickly in a less fasciculative manner, and, generally, more cell bodies leave the more flattened explant core (Fig. 1). Three days after the addition of antibodies to the cultures, neurites have formed a profuse halo around the explant core, displaying less tendency to fasciculate, particularly at the periphery (Figs. 2 and 3). The number of neurites does not appear to be drastically reduced in the presence of L1 antibodies (Figs. 2 and 3). Although some fascicles are still visible in L1 antibody-treated cultures, they are generally much thinner than in control cultures. Furthermore, neurite tips and growth cones show a significantly reduced degree of adhesion to each other in L1 antibody-treated cultures, whereas in control cultures, single processes are rarely seen (Fig. 5). So far, we have not found an influence of $\mathrm{Ll}$ antibodies on the mobility of growth cones, as revealed by time-lapse cinematography. Movement and association of oligodendrocytes with neurites is not changed in the presence of $\mathrm{Ll}$ antibodies. The outgrowth pattern of astrocytes is not different from that of control cultures (Fig. 2), nor is the spatial relationship of neuronal cell bodies and astrocytic processes changed (for control, see Fig. 4). However, the number of neuronal cell bodies that move away from the explant core is increased (Fig. 2, $C, F$ ).

Addition of Fab fragments from poly-and monoclonal N-CAM antibodies to the cultures results in similar effects as were observed with L1 antibodies: reduction in fasciculation, increased rate of neurite extension, increased number of neuronal cell bodies leaving the explant core, and unchanged relative position of neuronal cell bodies and astrocytic processes. Figure 3 shows five representative micrographs of microexplant cultures after $4 \mathrm{~d}$ of maintenance with and without $\mathrm{L} 1$ and N-CAM antibodies.

An attempt was made to quantify the observed effects. Extent of neurite outgrowth, pattern of neurite fasciculation, and movement of neuronal cell bodies away from the explant core were taken as the most characteristic features and the most reliably quantifiable parameters (Figs. 7 and 8 ). These parameters were described as categories (see the legend to Fig. 7) and were studied semiquantitatively during the period of 1-3 d after addition of $\mathrm{L} 1$ and N-CAM antibodies. It is evident that the observations on rate of neurite extension, fasciculation, and neuron movement in the absence and presence of Fab fragments of poly- and monoclonal L1 and N-CAM antibodies, described in the previous paragraphs, agree with the quantitative measurements (Fig. 8). Monoclonal Ll antibodies show a somewhat more pronounced effect than polyclonal L1 antibodies at the same concentrations, with regard to neurite outgrowth, fasciculation of neurites, and movement of neuronal cell bodies, particularly $2 \mathrm{~d}$ after addition of antibodies to the cultures.

Controls for the specificity of the effects of L1 antibodies consisted of the addition of other antibodies or choleragenoid to the explant cultures. Fab fragments of antibodies from preimmune rabbit serum, and the $\mathrm{GM}_{1}$ ganglioside binding choleragenoid have no effect at concentrations of 1 and $0.05 \mathrm{mg} / \mathrm{ml}$, respectively. However, Fab fragments of all antibodies tested so far that are directed against the cell surface of all or some cell types in the explant change the patterns of neurite outgrowth 

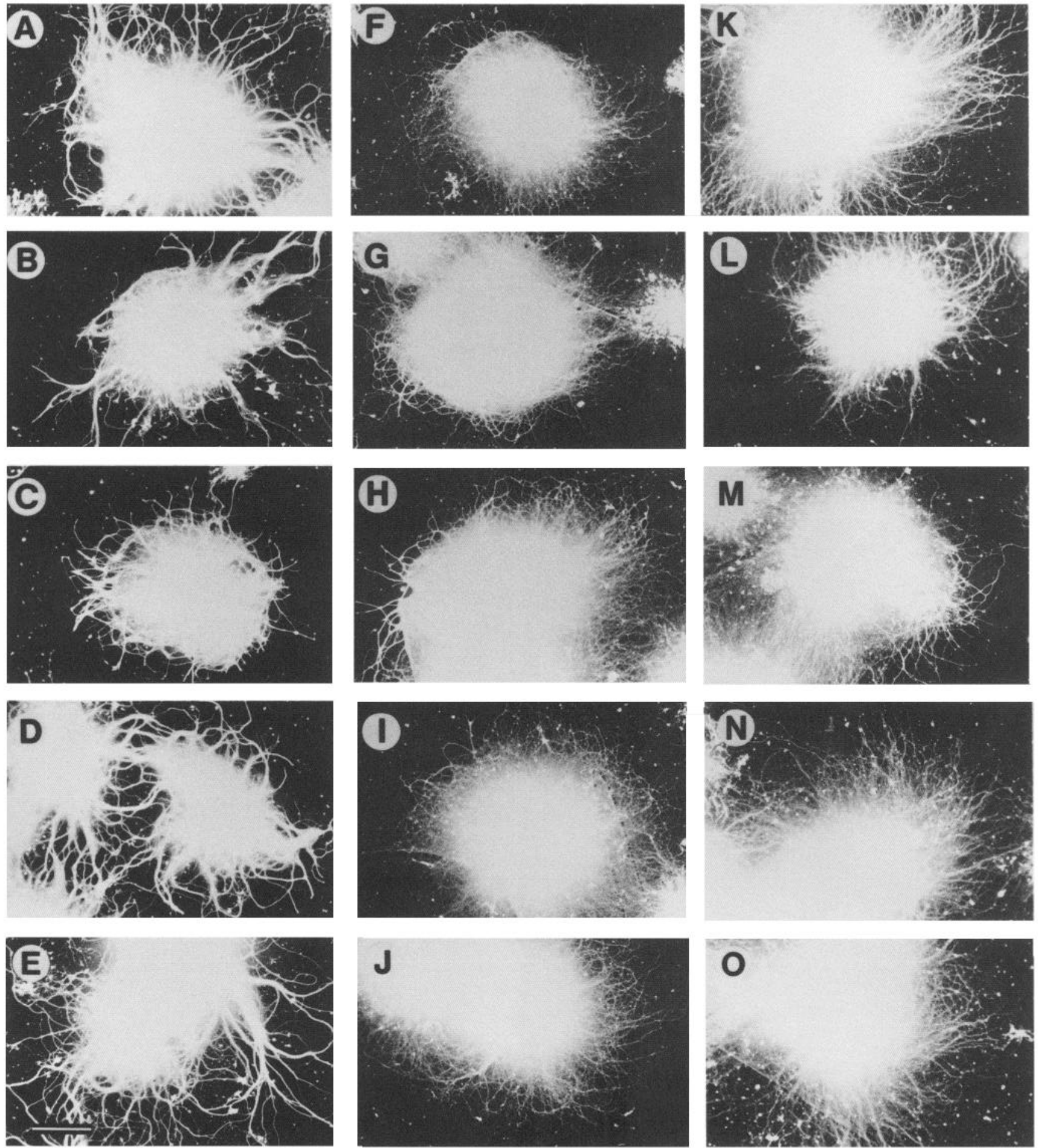

Figure 3. Cerebellar microexplant cultures after $4 \mathrm{~d}$ in vitro without antibodies $(A-E)$, and supplemented with Fab fragments of monoclonal L1 $(F-J)$ or monoclonal N-CAM $(K-O)$ antibodies $(0.5 \mathrm{mg} / \mathrm{ml}) 16 \mathrm{hr}$ after plating. Cultures were fixed and stained with RITC. Five representative micrographs for control and antibody-treated cultures are given for assessment of experimental variability. To visualize neurites in the periphery, fluorescence micrographs had to be overexposed. This resulted in obscuring the boundary between the explant core and adjacent outgrowth zone. Bar, $300 \mu \mathrm{m}$.

and/or cell-body movement. These are polyclonal antibodies to mouse liver membranes (Lindner et al., 1983), monoclonal L2 antibodies (Kruse et al., 1984), monoclonal antibodies M2, M5, and M6 (Lagenaur and Schachner, 1981; Lagenaur et al., unpublished observations). However, the particular character of interference with the outgrowth patterns was distinctly different from antibody to antibody in all parameters investigated (not shown). It is noteworthy that Fab fragments of polyclonal liver membrane and monoclonal L2 antibodies do not interfere with neurite fasciculation. 

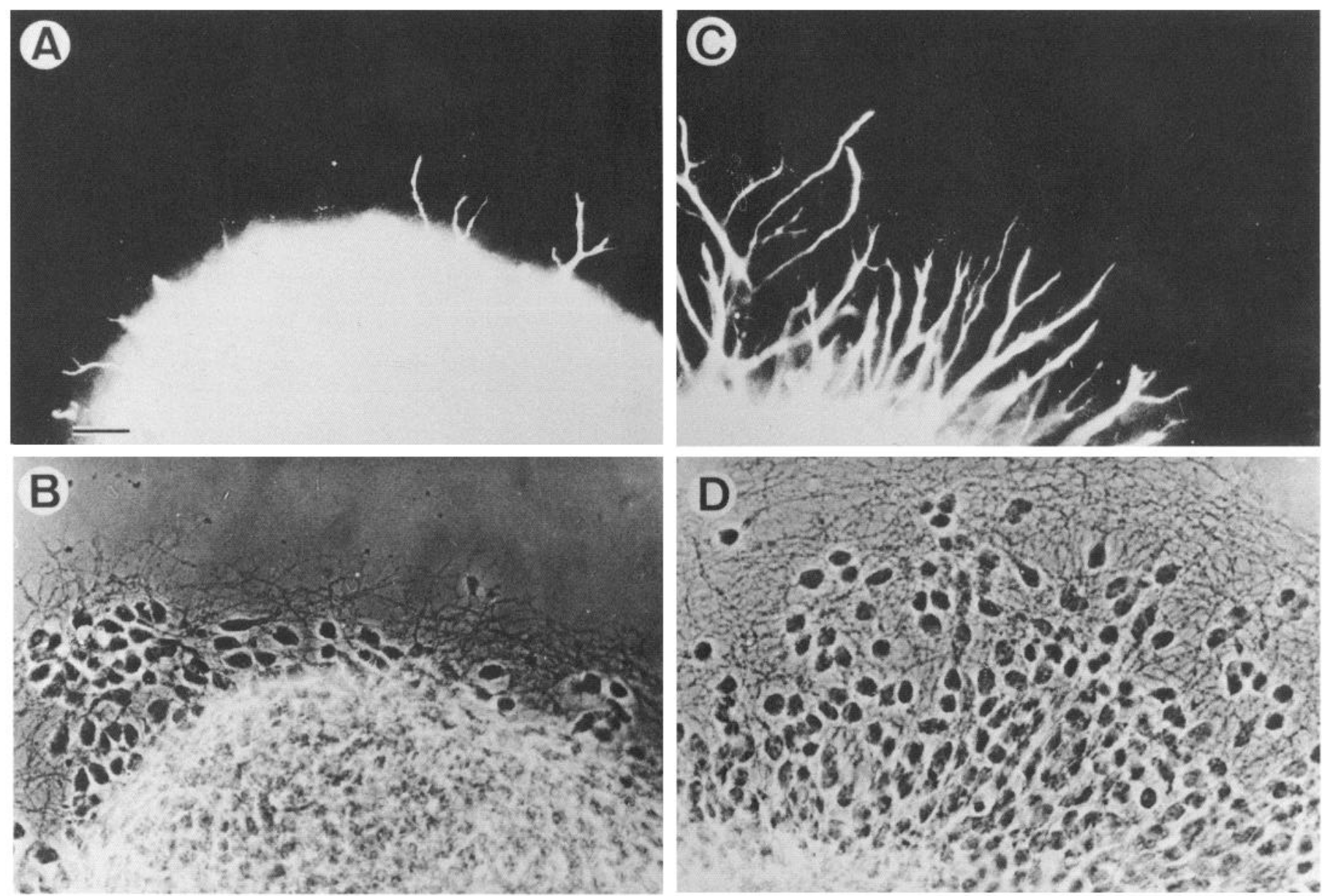

Figure 4. Immunolabeling of cerebellar microexplant cultures after $2(A, B)$ and $3(C, D) \mathrm{d}$ in vitro for GFA protein $(A, C)$. $B$ and $D$, Corresponding phase-contrast micrographs of $A$ and $C$, respectively. Bar, $25 \mu \mathrm{m}$.
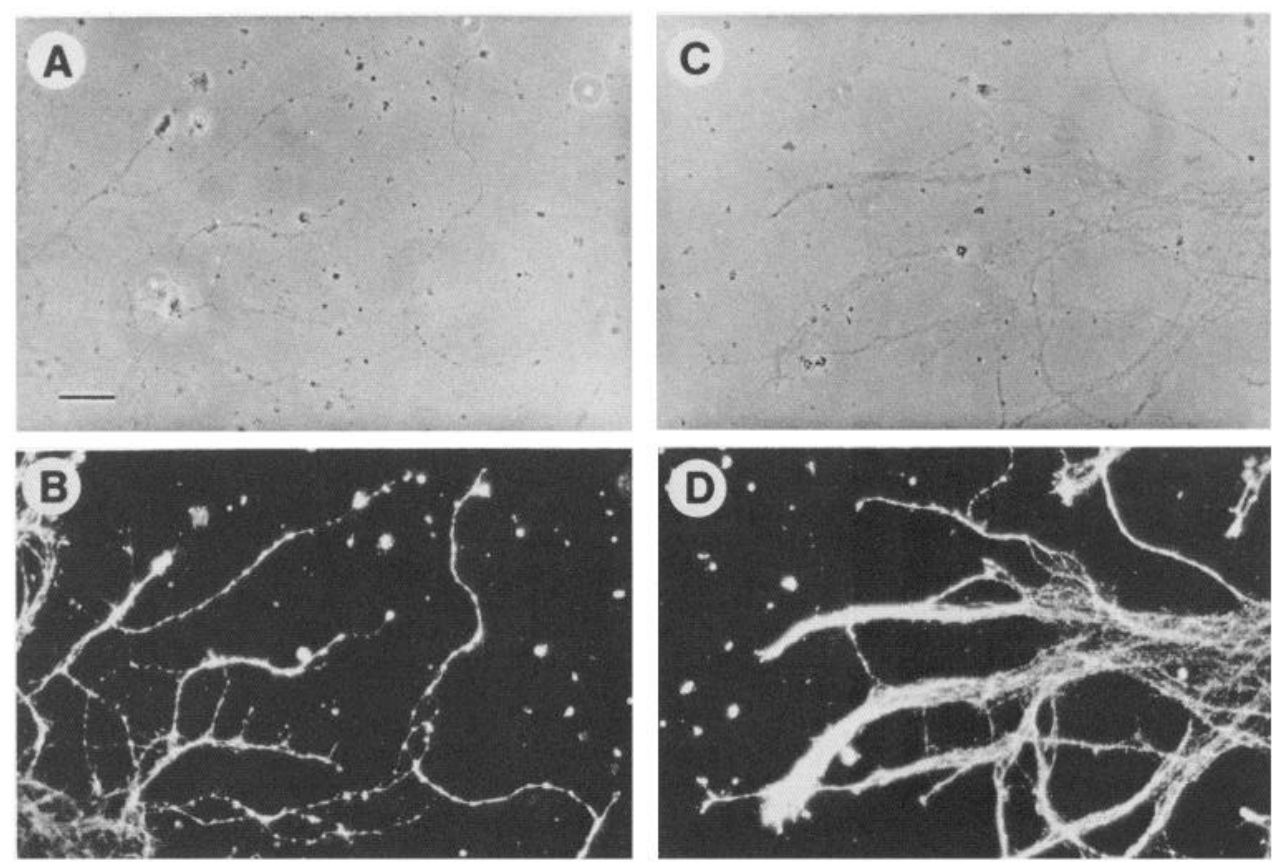

Figure 5. Microexplant cultures grown in the presence $(A, B)$ and absence $(C, D)$ of Fab fragments of monoclonal L1 antibodies. Microexplants were maintained as described in Fig. 2. Cultures were immunolabeled for tetanus toxin receptors $(B, D)$. Phasecontrast micrographs of the corresponding microscopic fields are shown in $A$ and $C$ for $B$ and $D$, respectively. Bar, $25 \mu \mathrm{m}$. 

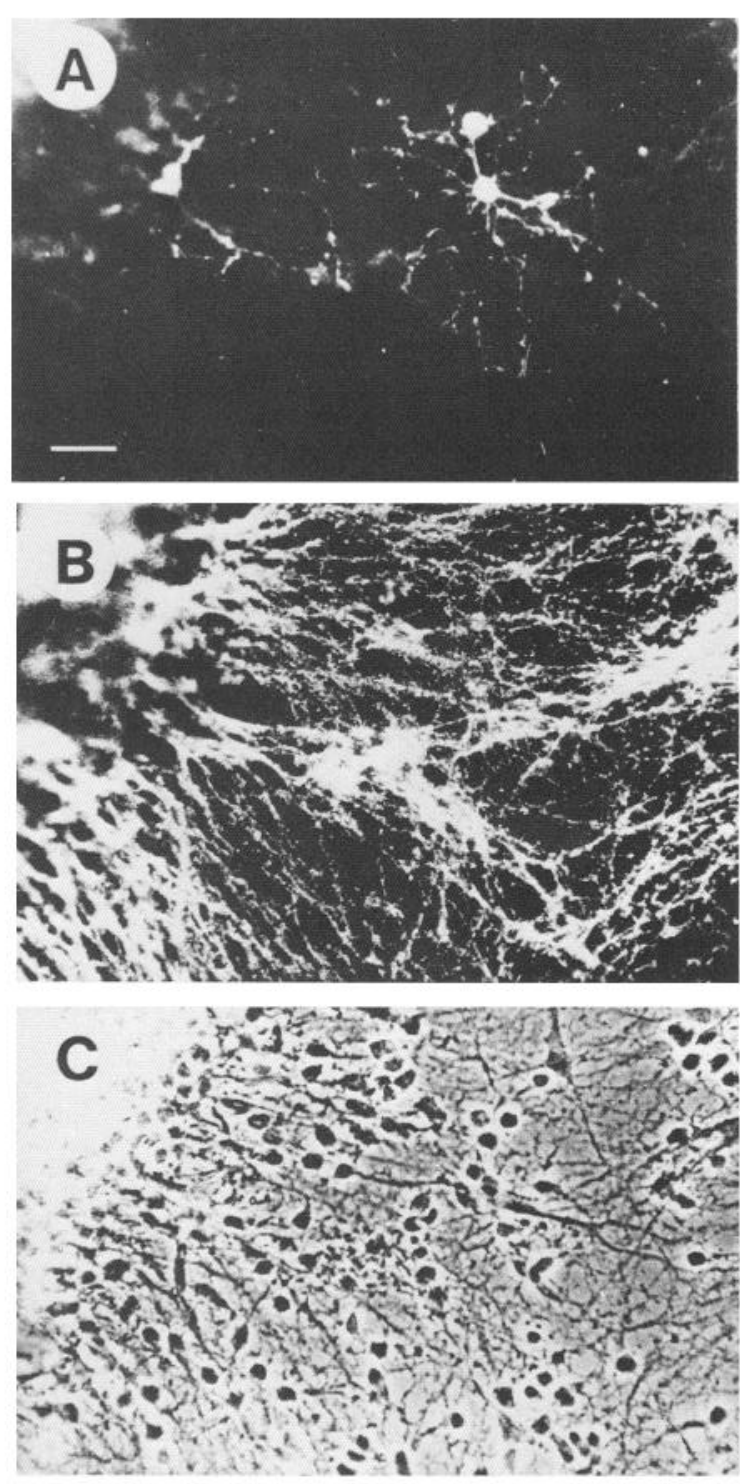

Figure 6. Immunodouble-labeling of cerebellar microexplant cultures after $4 \mathrm{~d}$ in culture for $\mathrm{O} 4(A)$ and $\mathrm{L} 1(B)$ antigens. Phase-contrast micrograph of the corresponding microscopic field is shown in $(C)$. Bar, $40 \mu \mathrm{m}$.

\section{Discussion}

The present study has shown that Fab fragments of L1 antibodies induce changes in the speed and pattern of neurite outgrowth in microexplants from the mouse cerebellar cortex without apparent reduction in number of neurites. In addition, there is a slight, but significant, influence on the outward movement of neurons. The effect of L1 antibodies on fasciculation is considered specific, since choleragenoid or antibodies to liver membranes, or monoclonal L2 antibodies, which bind to the cell surfaces of cerebellar cells, do not inhibit fasciculation of neurites. Interestingly, N-CAM antibodies have very similar effects on the fasciculation pattern and movement of neuronal cell bodies to L1 antibodies. However, we have not yet found an antibody that reacts with the surfaces of some or all cell types present in the explants and does not interfere with at least one feature in outgrowth patterns. Specific effects of antibodies under study can therefore only be interpreted in comparison with other, cell surface-reactive ones. It is noteworthy that another complex culture system, designed to reveal the migration of granule

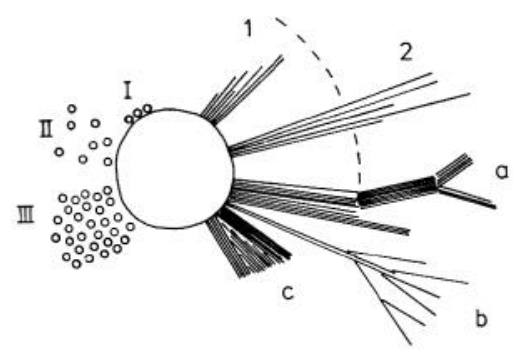

Figure 7. Schematic presentation of neuron migration, neurite outgrowth, and fasciculation patterns in cerebellar microexplant cultures. These categories were chosen to allow the semiquantitative evaluation of the salient features in outgrowth patterns, which can be assessed confidently at the light-microscopic level. Electron-microscopic determinations of neurite numbers and orientations were not considered feasible for statistical evaluations. Identification of neuronal cell bodies and processes is based on immunolabeling for L1 antigen or tetanus toxin receptors. Roman numbers refer to distribution of neuronal cell bodies around the explant core. $I$, Cell bodies in close vicinity of the explant core. $I I$, Cell bodies localized away from the explant core by a distance $>5 \times$ their diameter in a loosely packed distribution. III, Cell bodies localized at a distance from the explant core, which is $>10 \times$ their diameter, but, unlike $I I$, in a more densely packed distribution. Arabic numbers refer to distance covered by cellular processes. 1 , Cellular processes remain within ca. 1 diameter of the explant core $(<250$ $\mu \mathrm{m}$ long). 2, Cellular processes are found at distances larger than the diameter of the explant core ( $>250 \mu \mathrm{m}$ long), at the periphery in the cell-free outgrowth zone. Letters, The fasciculation pattern of neurites: $a$, Processes form thick fasciculating bundles ( $>3 \mu \mathrm{m}$ in diameter); growth cones rarely extend beyond these bundles. $b$, Processes form thinner bundles ( $<3 \mu \mathrm{m}$ in diameter) and numerous growth cones remain separated from each other. $c$, Processes form a continuous sheet of bundles without extending single processes.

cell neurons (Lindner et al., 1983), was less sensitive to perturbations by a variety of reagents, including monoclonal antibodies M2, polyclonal antibodies from rabbits against mouse liver membranes, and tetanus and cholera toxins (Lindner et al., 1983; Lindner and Schachner, unpublished observations).

Neurite fasciculation is predominantly modified, in the presence of L1 and N-CAM antibodies, in the periphery of the outgrowth zone, and less on the layer of astrocytic processes. Oligodendrocytes do not interfere with fasciculation of neurites, either in the absence or presence of $\mathrm{Ll}$ antibodies. These observations point to an influence of a type of substrate on formation of fascicles between neurites. A possible interpretation of these findings is that the interaction of neurites and astrocytes is so strong that the formation of larger fascicles is not favored (see Noble et al., 1984) and that consequently, a reduction of adhesive forces between neurites by $\mathrm{L} 1$ antibodies does not play a significant role in altering neurite fasciculation on astrocytes. Conversely, the interaction of neurites at the periphery of the outgrowth zone with the poly-D-lysine substrate, which is probably modified by cell secretion products (see, e.g., Gundersen and Barrett, 1984), is weaker, so that the formation of fascicles between neurites would be enhanced and an L1 antibody-mediated decreased affinity between neurites would become evident. Enhancement in speed of neurite outgrowth in the presence of $\mathrm{L} 1$ antibodies could also be interpreted as resulting from a delicate balance of adhesive forces between the neurite shafts themselves, and between neurites and substrate. A release from the constraints of adhesive forces between adjacent neurites could result in an accelerated outgrowth of neurites. Previous attempts to interfere with the fasciculation of axons in parallel fiber-like configuration, both in long-term reaggregate cultures of cells from early postnatal mouse cerebellum (Lindner et al., 1985) and in neurites extending from explants of mouse dorsal root ganglia (Schachner et al., 1983), have failed, probably because neurite-environment affinities were stronger than those 

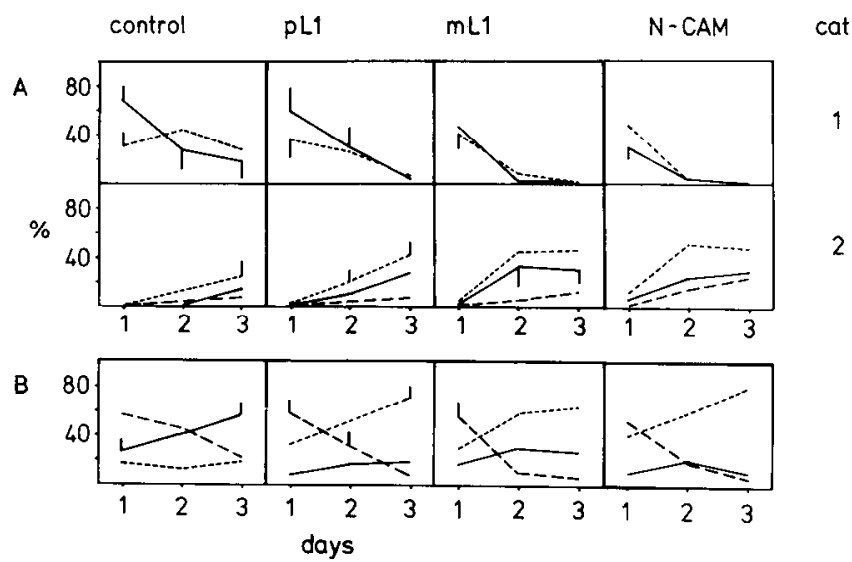

Figure 8. Distribution of neuronal cell bodies and outgrowth pattern of neurites in cerebellar microexplant cultures as a function of time in the absence (control) or presence of Fab fragments of polyclonal $(p L I)$, or monoclonal $(m L 1) \mathrm{L} 1$ and monoclonal N-CAM $(N-C A M)$ antibodies at concentrations of $0.3-0.7 \mathrm{mg} / \mathrm{ml}$. No differences were seen within this concentration range. Antibodies were added as described in Figure 2. $A$, To correlate the extent of neurite outgrowth $(1$ and 2$)$ with pattern of cell-body distribution (I, II, and III; see Fig. 7), the following evaluation scheme was adopted: After assigning individual explants to their arabic and roman categories, the total numbers of explants were summed up and taken as $100 \%$. Then the percentage distributions of categories I-III were calculated separately within the group of explants of catcgory 1 (cat. I) and within the group of explants of category 2 (cat. 2). (I, -; $I I,----; I I I,---) . B$, Fasciculation patterns were analyzed according to categories $a, b$, and $c$ (see Fig. 7). Total numbers were summed up and taken as $100 \%$. Values are given as percentage distributions. $(a,-$; $b,-\cdots ; c,---)$. Five independent experiments with mono- and polyclonal $\mathrm{L} 1$ antibodies and two independent experiments with monoclonal N-CAM antibodies were carried out. For each time point, at least two to three coverslips with 35 to 55 microexplants each were evaluated for each experiment. SEMs indicated only when they exceed $10 \%$. Abscissa, Days in vitro after addition of antibodies ( $16 \mathrm{hr}$ after plating).

among neurites, or were not easily amenable to quantification (Lindner et al., 1985). Whether the balance of adhesive forces revealed in the present microexplant culture system indeed corresponds to the situation in the intact tissue remains to be established. However, since, in the developing cerebellar cortex, the outgrowing axons of granule cell neurons are in close apposition to each other, and relatively undisturbed by glial processes, some of these features may be reflected in the microexplant culture system. We therefore suggest that L 1 antigen may be involved in the orientation and alignment of outgrowing granule cell axons and maintenance in their parallel fiber configuration in the adult state. The fact that $\mathrm{Ll}$ antigen plays a role in neurite fasciculation in vitro appears to correlate with the observation that, in the embryonic mouse spinal cord, L1 antigen is present on fasciculating, but not on nonfasciculating, axons (J. Holley and M. Schachner, unpublished observations). Here, one and the same axon differentially expresses Ll antigen, depending on whether it is in a fasciculative or nonfasciculative state. Furthermore, axons, but not dendrites, have been obscrved to express Ll antigen in the mouse embryonic spinal cord (J. Holley and M. Schachner, unpublished observations). That axons may also use other adhesive forces is not unlikely, since N-CAM is expressed by parallel fibers in mouse cerebellum in situ (Langley et al., 1982) and N-CAM antibodies interfere with fasciculation of neurites in the present culture system. In addition, Fab fragments of N-CAM antibodies have been shown to reduce neurite fasciculation in cultures of spinal ganglia ( $\mathrm{Ru}-$ tishauser and Edelman, 1980; Rutishauser et al., 1978). However, in contrast to L1 antigen, N-CAM is expressed at earlier developmental stages, not only on neurons, but on glial cells as well (Keilhauer and Schachner, 1985), and not only on axons, but also on dendrites. Thus a broader spectrum of morphogenetic functions has to be postulated for N-CAM.

With regard to the more extensive outward movement of small neuronal cell bodies from the explant core, a question arises about the guiding cellular mechanisms. It is noteworthy that the cell bodies do not need an astrocytic carpet for migration and may move in association with neurites. This does not rule out, however, the possibility that neurons can migrate on astrocytic processes if they are present, as has been observed in vivo (Rakic, 1971) and in vitro (Hatten et al., 1984). However, in our culture system, timing and extent of neuron movement, particularly in the early outgrowth phases, are quite independent of astrocytes. It is conceivable, therefore, that the extent of migration is unrelated to astrocytes and intrinsic to granule cell neurons themselves (Trenkner et al., 1984). An influence of L1 antibodies on neuron movement along neurites or in association with other neurons is not unlikely, since it can be shown that L1 antibodies inhibit neuron-to-neuron (Faissner et al., 1984a; Rathjen and Schachner, 1984), but not neuron-to-astrocyte or astrocyte-to-astrocyte adhesion (Keilhauer and Schachner, 1985). We would like to suggest, therefore, that in microexplant cultures, neurons that are predominantly postmitotic in this system (unpublished observations) display adhesive forces to each other and to neurites, and that when these are reduced in the presence of L1 antibodies, neurons become more mobile. Interestingly, in a different, suspension explant culture system, L1 antibodies inhibit rather than promote migration of granule cell neurons from the outer to the inner granular layer (Lindner et al., 1983). We therefore speculate that in the latter system, neuron-toneuron adhesion, or the "sorting out" of postmitotic neurons from the L1 antigen-negative proliferating ones in the external granular layer, is L1 antigen-dependent and a prerequisite for migration of granule cells. Alternatively, fasciculation of granule cell axons as parallel fibers in the nascent molecular layer may be a necessary condition for migration of cell bodies. The elucidation of the physiological role of L1 antigen during cerebellar development in vivo remains a topic for further investigation.

\section{References}

Amante, L., A. Ancona, and L. Forni (1972) The conjugation of immunoglobulins with tetramethylrhodamine isothiocyanate: A comparison between the amorphous and the crystalline fluorochrome. $J$. Immunol. Methods 1: 289-301.

Bignami, A., L. F. Eng, D. Dahl, and C. T. Uyeda (1972) Localization of the glial fibrillary acidic protein in astrocytes by immunofluorescence. Brain Res 43: 429-435.

Cowan, W. M. (1982) A synoptic view of the development of the vertebrate central nervous system. In Repair and Regeneration of the Nervous System, Life Sciences Research Reports 24, J. G. Nicholls, ed., pp. 7-24, Springer-Verlag, Heidelberg, Berlin, New York.

Faissner, A., J. Kruse, C. Goridis, E. Bock, and M. Schachner (1984a) The neural cell adhesion molecule $\mathrm{Ll}$ is distinct from the N-CAM related group of surface antigens BSP-2 and D2. FMBO J. 3: 733737.

Faissner, A., J. Kruse, J. Nieke, and M. Schachner (1984b) Expression of neural cell adhesion molecule $L 1$ during development, in neurological mutants and in the peripheral nervous system. Dev. Brain Res. 15: 69-82.

Fischer, G. (1982) Cultivation of mouse cerebellar cells in serum-free, hormonally defined media: Survival of neurons. Neurosci. Lett. 28: 325-329.

Goridis, C., H. Deagostini-Bazin, M. Hirn, M.-R. Hirsch, G. Rougon, R. Sadoul, O. K. Langley, G. Gombos, and J. Finne (1983) Neural surface antigens during nervous system development. Cold Spring Harbor Symp. Quant. Biol. 48: 527-538.

Greene, L. A., and E. M. Shooter (1982) Nerve growth factor: Biochemistry, synthesis and mechanism of action. Annu. Rev. Neurosci. 3: 353-402.

Gundersen, R. W., and J. N. Barrett (1984) Neurite growth conesubstratum adherence increases in vitro. Dev. Brain Res. 12:21-26. Hatten, M. E., R. K. H. Liem, and C. A. Mason (1984) Two forms 
of cerebellar glial cells interact differently with neurons in vitro. J. Cell Biol. 98: 193-204.

Keilhauer, G., and M. Schachner (1985) Differential inhibition of neuron-neuron, neuron-astrocyte and astrocyte-astrocyte adhesion by L1, L2 and N-CAM antibodies. Nature 316: 728-730.

Kruse, J., R. Mailhammer, H. Wernecke, A. Faissner, I. Sommer, C. Goridis, and M. Schachner (1984) Neural cell adhesion molecules and myelin associated glycoprotein share a common, developmentally early carbohydrate moiety recognized by monoclonal antibodies $\mathrm{L} 2$ and HNK-1. Nature 311: 153-155.

Lagenaur, C., and M. Schachner (1981) Monoclonal antibody (M2) to glial and neuronal cell surfaces. J. Supramol. Struct. Cell. Biochem. 15: 335-348.

Lander, A. D., K. Tomaselli, A. L. Calof, and L. F. Reichardt (1983) Studies on extracellular matrix components that promote neurite outgrowth. Cold Spring Harbor Symp. Quant. Biol. 48: 611-623.

Landis, S. C. (1983) Neuronal growth cones. Annu. Rev. Physiol. 45: 567-580.

Langley, O. K., M. S. Ghandour, G. Gombos, M. Hirn, and C. Goridis (1982) Monoclonal antibodies as neural cell surface markers. Neurochem. Res. 7: 349-362.

Letourneau, P. C. (1983) Axonal growth and guidance. Trends Neurosci. 6: $451-455$.

Lindner, J., P. M. Orkand, and M. Schachner (1985) Histotypic pattern formation in cerebellar reaggregate cultures in the presence of antibodies to L1 cell surface antigen. Neurosci. Lett. 55: 145-149.

Lindner, J.., F. G. Rathjen, and M. Schachner (1983) L1 mono- and polyclonal antibodies modify cell migration in early postnatal mouse cerebellum. Nature 305: 427-430.

Moonen, G., E. A. Neale, R. L. Macdonald, W. Gibbs, and P. G. Nelson (1982) Cerebellar macroneurons in microexplant cell culture. Methodology, basic electrophysiology, and morphology after horseradish peroxidase injection. Dev. Brain Res. 5: 59-73.

Noble, M., J. Fok-Seang, and J. Cohen (1984) Glia are a unique substrate for the in vitro growth of central nervous system neurons. J. Neurosci. 4: 1892-1903.
Rakic, P. (1971) Neuron-glia relationship during granule cell migration in developing cerebellar cortex. A Golgi and electron microscopic study in Macacus Rhesus. J. Comp. Neurol. 141: 282-312.

Rathjen, F. G., and M. Schachner (1984) Immunocytological and biochemical characterization of a new neuronal cell surface component (L1 antigen) which is involved in cell adhesion. EMBO J. 3: 110.

Rathjen, F. G., B. Holcombe, and A. Gierer (1981) Separation of cell populations from embryonic chick neural retina with fluorescenceactivated cell sorting. J. Biochem. Biophys. Methods 4: 191-207.

Rutishauser, U., and G. M. Edelman (1980) Effects of fasciculation on the outgrowth of neurites from spinal ganglia in culture. J. Cell Biol. 87: 370-378.

Rutishauser, U., W. E. Gall, and G. M. Edelman (1978) Adhesion among neural cells of the chick embryo. IV. Role of the cell surface molecule CAM in the formation of neurite bundles in cultures of spinal ganglia. J. Cell Biol. 79: 382-393.

Schachner, M., A. Faissner, J. Kruse, J. Lindner, D. H. Meier, F. G. Rathjen, and H. Wernecke (1983) Cell-type specificity and developmental expression of neural cell surface components involved in cell interactions and of structutally related molecules. Cold Spring Harbor Symp. Quant. Biol. 48: 557-568.

Schnitzer, J., and M. Schiachner (1981) Expression of Thy-1, H-2 and NS-4 cell surface antigens and tetanus toxin receptors in the developing and adult mouse cerebellum. J. Neuroimmunol. 1: 429-456.

Schnitzer, J., W. W. Franke, and M. Schachner (1981) Immunocytochemical demonstration of vimentin in astrocytes and ependymal cells of developing and adult mouse nervous system. J. Cell Biol. 90: $435-475$.

Sommer, I., and M. Schachner (1981) Monoclonal antibodies (O1 to O4) to oligodendrocyte cell surfaces: An immunocytological study in the central nervous system. Dev. Biol. 83: 311-327.

Trenkner, E., D. Smith, and N. Segil (1984) Is cerebellar granule cell migration regulated by an internal clock? J. Neurosci. 4: 2850-2855. 